\title{
High-resolution snow depth prediction using Random Forest algorithm with topographic parameters and an ecosystem map: a case study in the Greiner Watershed, Nunavut
}

\author{
Julien Meloche ${ }^{1}$, Alexandre Langlois ${ }^{1}$, Nick Rutter ${ }^{2}$, Don McLennan ${ }^{3}$, Alain Royer ${ }^{4}$, Paul \\ Billecocq ${ }^{1}$, and Serguei Ponomarenko ${ }^{5}$ \\ ${ }^{1}$ Université de Sherbrooke \\ ${ }^{2}$ Northumbria University \\ ${ }^{3}$ Arctic Research Fondation \\ ${ }^{4}$ Universite de Sherbrooke \\ ${ }^{5}$ Polar Knowledge Canada
}

November 24, 2021

\begin{abstract}
Increased surface temperatures ( 0.7 per decade) in the Arctic affects polar ecosystems by reducing the extent and duration of annual snow cover. Monitoring of these important ecosystems needs detailed information on snow cover properties (depth and density) at resolutions $(<100 \mathrm{~m})$ that influence ecological habitats and permafrost thaw. As arctic snow is strongly influenced by vegetation, an ecotype map at $10 \mathrm{~m}$ resolution was added to a method with the Random Forest (RF) algorithm previously developed for alpine environments and applied here over an arctic landscape for the first time. The topographic parameters used in the RF algorithm were Topographic Position Index (TPI) and up-wind slope index (Sx), which were estimated from the freely available Arctic DEM at $2 \mathrm{~m}$ resolution. Ecotypes with taller vegetation with moister soils were found to have deeper snow because of the trapping effect. Using feature importance with RF, snow depth distributions were predicted from topographic and ecosystem parameters with a root mean square error $=8 \mathrm{~cm}(23 \%)\left(\mathrm{R}^{2}=0.79\right)$ at $10 \mathrm{~m}$ resolution for an arctic watershed $\left(1500 \mathrm{~km}^{2}\right)$ in western Nunavut, Canada.
\end{abstract}

\section{Hosted file}

Snow_randomForest_V12.docx available at https://authorea.com/users/447864/articles/546782high-resolution-snow-depth-prediction-using-random-forest-algorithm-with-topographicparameters-and-an-ecosystem-map-a-case-study-in-the-greiner-watershed-nunavut 


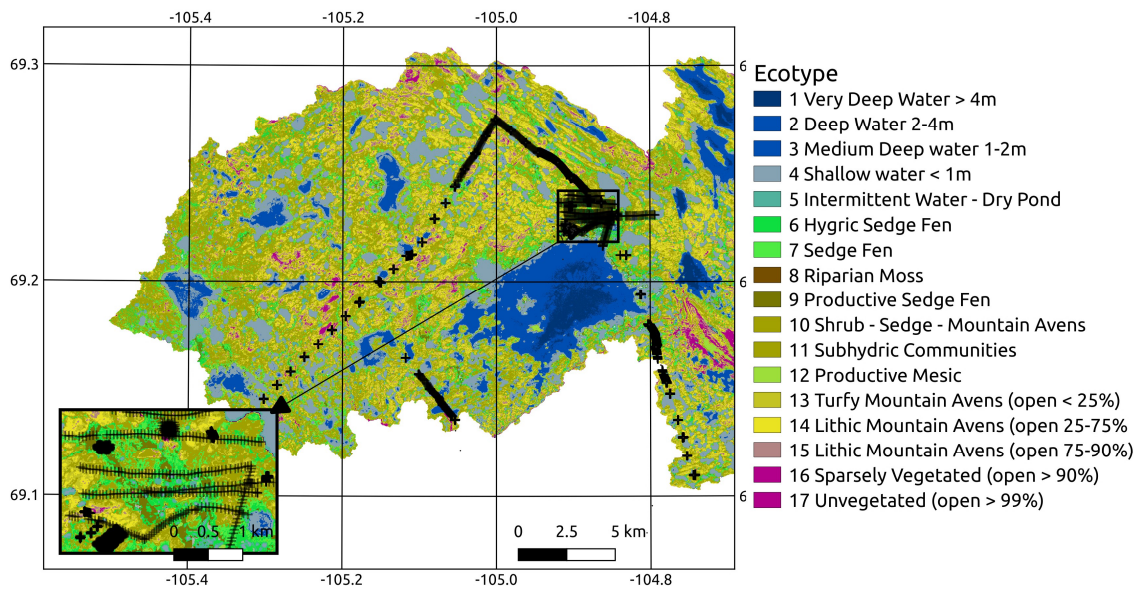

Ecosystem - Vegetation height $(\mathrm{cm})$

Soil Moisture Regime

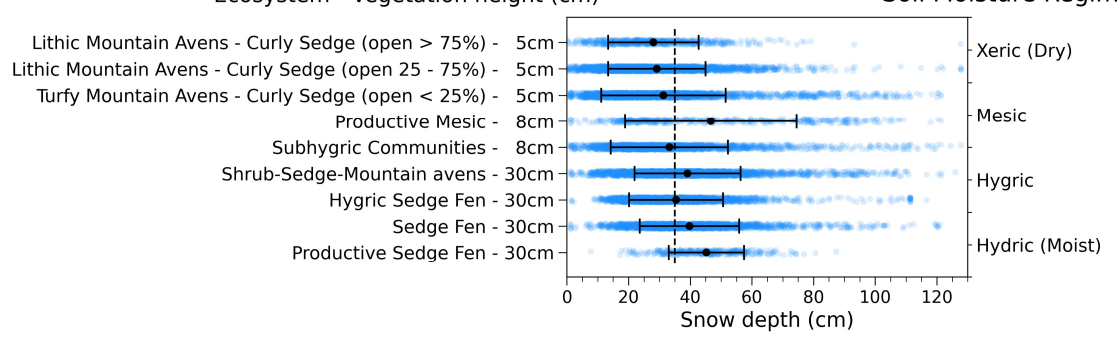


a)
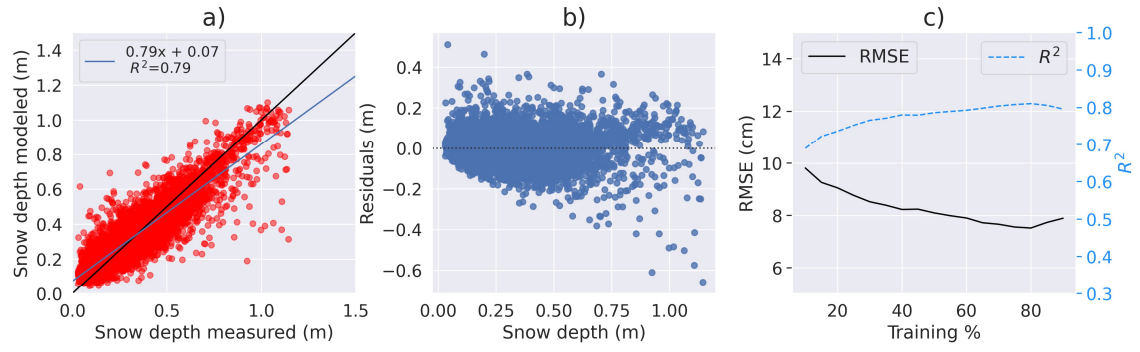

a)

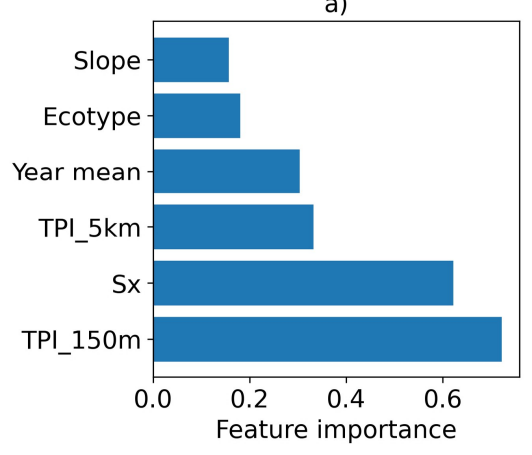

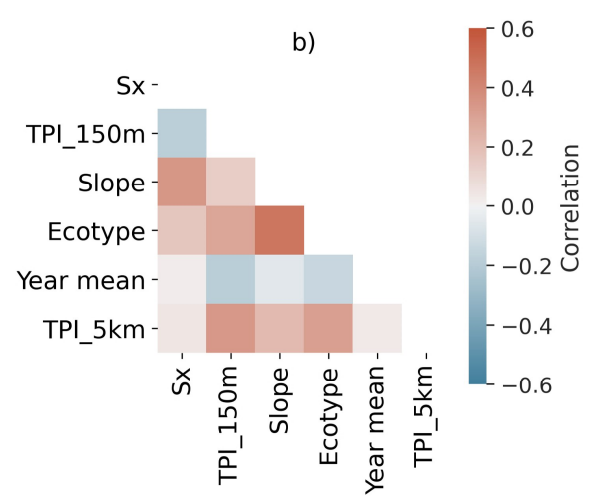



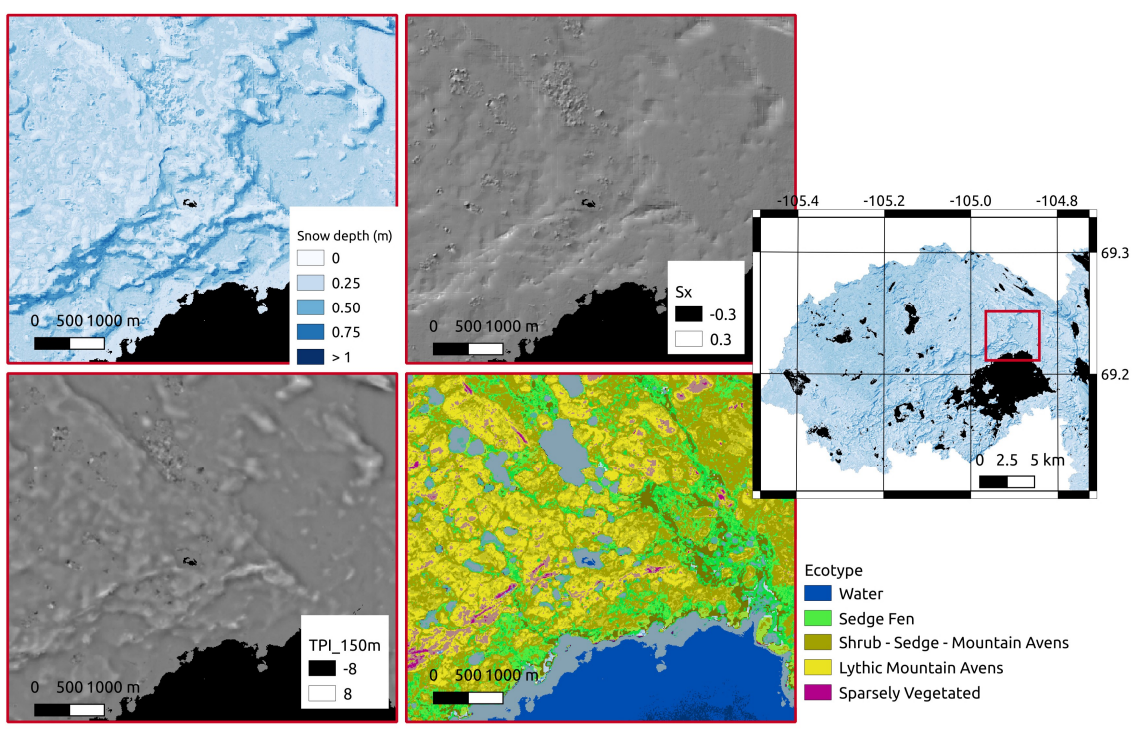